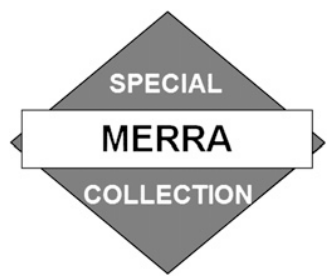

\title{
Assessment and Enhancement of MERRA Land Surface Hydrology Estimates
}

\author{
Rolf H. Reichle AND RANDAL D. KosteR \\ Global Modeling and Assimilation Office, NASA Goddard Space Flight Center, Greenbelt, Maryland \\ GABRIËLlE J. M. DE LANNOY \\ Global Modeling and Assimilation Office, NASA Goddard Space Flight Center, Greenbelt, and Goddard Earth Sciences \\ and Technology Center, University of Maryland, Baltimore County, Baltimore, Maryland, and Laboratory \\ of Hydrology and Water Management, Ghent University, Ghent, Belgium

\section{BARTON A. FORMAN} \\ Global Modeling and Assimilation Office, NASA Goddard Space Flight Center, Greenbelt, Maryland, and Oak Ridge \\ Associated Universities, Oak Ridge, Tennessee

\section{QING LiU AND SARITH P. P. MAHANAMA} \\ Global Modeling and Assimilation Office, NASA Goddard Space Flight Center, Greenbelt, and Science Applications \\ International Corporation, Beltsville, Maryland
}

\section{Ally TOURÉ}

Global Modeling and Assimilation Office, NASA Goddard Space Flight Center, Greenbelt, and Goddard Earth Sciences and Technology Center, University of Maryland, Baltimore County, Baltimore, Maryland

(Manuscript received 23 December 2010, in final form 16 April 2011)

\begin{abstract}
The Modern-Era Retrospective Analysis for Research and Applications (MERRA) is a state-of-the-art reanalysis that provides, in addition to atmospheric fields, global estimates of soil moisture, latent heat flux, snow, and runoff for 1979-present. This study introduces a supplemental and improved set of land surface hydrological fields ("MERRA-Land") generated by rerunning a revised version of the land component of the MERRA system. Specifically, the MERRA-Land estimates benefit from corrections to the precipitation forcing with the Global Precipitation Climatology Project pentad product (version 2.1) and from revised parameter values in the rainfall interception model, changes that effectively correct for known limitations in the MERRA surface meteorological forcings. The skill (defined as the correlation coefficient of the anomaly time series) in land surface hydrological fields from MERRA and MERRA-Land is assessed here against observations and compared to the skill of the state-of-the-art ECMWF Re-Analysis-Interim (ERA-I). MERRA-Land and ERA-I root zone soil moisture skills (against in situ observations at 85 U.S. stations) are comparable and significantly greater than that of MERRA. Throughout the Northern Hemisphere, MERRA and MERRA-Land agree reasonably well with in situ snow depth measurements (from 583 stations) and with snow water equivalent from an independent analysis. Runoff skill (against naturalized stream flow observations from 18 U.S. basins) of MERRA and MERRA-Land is typically higher than that of ERA-I. With a few exceptions, the MERRA-Land data appear more accurate than the original MERRA estimates and are thus recommended for those interested in using MERRA output for land surface hydrological studies.
\end{abstract}

Corresponding author address: Rolf H. Reichle, NASA Goddard Space Flight Center, Mail Code 610.1, 8800 Greenbelt Road, Greenbelt, MD 20771.

E-mail: rolf.reichle@nasa.gov

\section{Introduction}

The Modern-Era Retrospective Analysis for Research and Applications (MERRA; Rienecker et al. 2011) is a recent addition to the suite of global, long-term reanalysis 
products that are based on the assimilation of in situ and remote sensing observations into numerical models of the global atmosphere and land surface (Kalnay et al. 1996; Kanamitsu et al. 2002; Uppala et al. 2005; Onogi et al. 2007; Dee et al. 2011; Saha et al. 2010). Besides estimates of atmospheric conditions, reanalysis products also provide estimates of land surface fields, including surface meteorological forcing data (such as precipitation, radiation, air temperature, and humidity) as well as land surface states and fluxes (such as soil moisture, snow, and runoff). Reanalysis estimates can be used for a large variety of research and applications, for example, the generation of enhanced land surface meteorological datasets (Berg et al. 2005; Guo et al. 2006; Sheffield et al. 2006), the study of the land surface water budget, including streamflow, droughts, soil moisture, and snow processes (Dai and Trenberth 2002; Su and Lettenmaier 2009; Sheffield and Wood 2008; Burke et al. 2010; Brown et al. 2010), the estimation of the land carbon budget (Zhao et al. 2006; Yi et al. 2011), and, possibly, the calibration and verification of seasonal climate forecasting systems (Saha et al. 2006) and the generation of climate data records (Thorne and Vose 2010; Dee et al. 2010).

The MERRA data products are available from 1979 to present at high spatial and temporal resolution and are based on the assimilation of a vast number of atmospheric observations. MERRA land surface estimates, however, utilize no directly assimilated land surface observations; they reflect instead the time integration of surface meteorological conditions (precipitation, radiation, wind speed, etc.) by the land model component of MERRA. Based on the analyzed atmospheric state (including humidity and temperature profiles), MERRA precipitation over land is generated by the atmospheric general circulation model (AGCM) during the Incremental Analysis Update segment (Rienecker et al. 2011) and is thus subject to considerable errors that ultimately propagate into the land surface hydrological fields. Moreover, errors in land surface estimates result from errors in the land surface model itself, including imperfect representation of physical processes and uncertainties in the land model parameters.

Given knowledge of such errors, it is reasonable to attempt to mitigate their impacts through the careful postprocessing of MERRA output. Such postprocessing, if done properly, could produce a land surface dataset more useful and appropriate for hydrological analyses. Here, we describe a particular postprocessing of the MERRA land fields that involves the reintegration of the land surface model with more realistic precipitation forcing and with a parameterization change designed to counteract certain known problems with MERRA's diurnal rainfall and radiation cycles. The resulting fields, along with the original MERRA land fields, are compared extensively to observations; advantages of the postprocessed dataset (hereinafter "MERRA-Land") are highlighted.

We emphasize that these known problems are typical of global reanalysis data products. On average, global precipitation from MERRA is no worse than estimates from other reanalysis products (Bosilovich et al. 2011). There have been many similar efforts to improve global offline land surface simulations through corrected analysis or reanalysis forcing data (e.g., Dirmeyer and Tan 2001; Berg et al. 2005; Guo et al. 2006; Qian et al. 2006; Sheffield et al. 2006). Our paper focuses on the land surface hydrology estimates from MERRA and how they can be improved through simple corrections to land model parameters and the precipitation forcing.

The paper is organized as follows. Section 2 briefly describes the MERRA modeling system and data product, along with the data used for its evaluation. Section 3 starts with a brief evaluation of MERRA surface precipitation and radiation estimates and motivates the development of the MERRA-Land product, which is described in detail thereafter. Section 4 evaluates MERRA and MERRALand estimates of interception loss fraction, latent heat flux, soil moisture, runoff, and snow. Additional discussion and conclusions follow in section 5. The appendix details the skill metric used herein.

\section{Data}

\section{a. The MERRA system and data product}

MERRA is a reanalysis product generated by the National Aeronautics and Space Administration (NASA) Global Modeling and Assimilation Office (GMAO) using the Goddard Earth Observing System (GEOS) version 5.2.0 (Rienecker et al. 2011; http://gmao.gsfc.nasa.gov/ research/merra/). The system incorporates information from in situ and remote sensing observations of the atmosphere, including many modern satellite observations such as Atmospheric Infrared Sounder (AIRS) radiances and scatterometer-based wind retrievals. These observations are assimilated into the GEOS-5 AGCM using the National Centers for Environmental Prediction Gridpoint Statistical Interpolation assimilation package. MERRA, however, does not include a land surface analysis. MERRA covers the period from 1979 to the present and continues to be updated with latency on the order of weeks. MERRA estimates of surface meteorological and land surface fields are available at hourly time steps and at $1 / 2^{\circ} \times 2 / 3^{\circ}$ resolution in latitude and longitude, respectively.

The GEOS-5 AGCM includes a set of state-of-the-art physics packages, along with the innovative GEOS-5 
Catchment land surface model (hereinafter Catchment model; Koster et al. 2000; Ducharne et al. 2000). The model is designed to improve the treatment of land surface hydrological processes through explicit modeling of subgridscale soil moisture variability and its effect on runoff and evaporation. The basic computational unit of the model is the hydrological catchment (or watershed), with boundaries defined by topography (see below). Within each element, the vertical profile of soil moisture is given by the equilibrium soil moisture profile and the deviations from the equilibrium profile (described by variables in a $0-2-\mathrm{cm}$ surface layer and in a "root zone" layer that extends from the surface to a depth $z_{R}$, with $75 \mathrm{~cm} \leq z_{R} \leq 100 \mathrm{~cm}$ depending on local soil conditions). The spatial variability of soil moisture is diagnosed at each time step from the bulk water prognostic variables and the statistics of the catchment topography. The soil and vegetation parameters used in the Catchment model are from the NASA GEOS-5 global modeling system (Rienecker et al. 2011). The Catchment model also includes a state-of-the-art snow model (Stieglitz et al. 2001); in each watershed, the evolution of snow water equivalent (SWE), snow depth, and snow heat content in response to surface meteorological conditions and snow compaction is modeled using three layers. The time step for the land model integration is $20 \mathrm{~min}$.

The Catchment model's computations are performed at a higher spatial resolution than those of the atmosphere. The basic land surface element, or "tile," is a topographically determined hydrological catchment; catchments that straddle AGCM grid cells are subdivided by the grid boundary into smaller tiles. Although standard MERRA output is available only on the $1 / 2^{\circ} \times 2 / 3^{\circ}$ grid, higher-resolution tile-based land surface fields are generated (but not saved) as part of the MERRA data production. For MERRA, the Catchment model uses 157051 land tiles with a mean (median) area of $828 \mathrm{~km}^{2}$ $\left(524 \mathrm{~km}^{2}\right)$, resulting in an average resolution of about $25 \mathrm{~km}$.

For this study, we "replayed" the MERRA land surface component by forcing the Catchment model offline (i.e., not coupled to the atmospheric model) after interpolation of the hourly land surface meteorological fields from the standard MERRA output to the 20-min Catchment model time step. The replay configuration produces output that is only marginally different from the original MERRA land surface fields, and it serves two important purposes. First, it allows us to conduct the skill assessment using the higher-resolution tile output and thereby lessen the impact of the discrepancy between the horizontally distributed scale of the model-based estimates and the point-scale of the validating in situ measurements. Second, the MERRA-Land estimates (discussed below) are based on the offline replay configuration by construction, and thus comparing them to the MERRA estimates generated offline under replay mode allows a more careful isolation of the impacts of the precipitation corrections and model parameter revisions on the accuracy of the product.

\section{b. Evaluation data}

\section{1) Precipitation observations}

We use the Global Precipitation Climatology Project (GPCP) precipitation pentad (5-day) product version 2.1 (Huffman et al. 2009; Xie et al. 2003) to evaluate and correct the MERRA precipitation estimates. The GPCP data are available as pentad averages from 1979 to 2009 on a $2.5^{\circ} \times 2.5^{\circ}$ global grid and are based on the merging of satellite measurements (infrared and microwave) with global rain gauge observations from the Global Precipitation Climatology Centre. Specifically, the GPCP pentad product is computed by adjusting the pentad estimates from the National Oceanic and Atmospheric Administration (NOAA) Climate Prediction Center (CPC) Merged Analysis of Precipitation (CMAP; Xie and Arkin 1997; http://www.esrl.noaa.gov/psd/data/gridded/data.cmap. $\mathrm{html}$ ) product to monthly GPCP version 2.1 estimates. GPCP and CMAP estimates differ primarily in the input and processing of the satellite observations and in the approach for combining the satellite and gauge inputs.

\section{2) SOIL MOISTURE OBSERVATIONS}

In situ soil moisture observations from the U.S. Department of Agriculture Soil Climate Analysis Network (SCAN; Schaefer et al. 2007, http://www.wcc.nrcs.usda. gov) are used to assess skill. Hourly soil moisture measurements were taken with a device measuring the dielectric constant of the soil (Stevens Water Hydra Probe sensors inserted horizontally at depths of 5,10,20, 50, and $100 \mathrm{~cm}$ wherever possible). There are a total of 125 SCAN sites in the contiguous United States that provide some data between 1 January 2002 and 31 July 2009, the period considered here (Fig. 1). For data from each SCAN site we applied extensive quality control steps that included automatic detection of problematic observations and a visual inspection of the time series. We excluded data that are obviously unrealistic (such as data outside of the physical range or data related to discontinuities in the time series that could not be explained by physical processes). We also excluded soil moisture measurements that were taken under frozen conditions (according to SCAN soil temperature measurements), or data affected by inconsistencies that are most likely due to changes in sensor calibration or sensor installation. After quality control of the hourly 


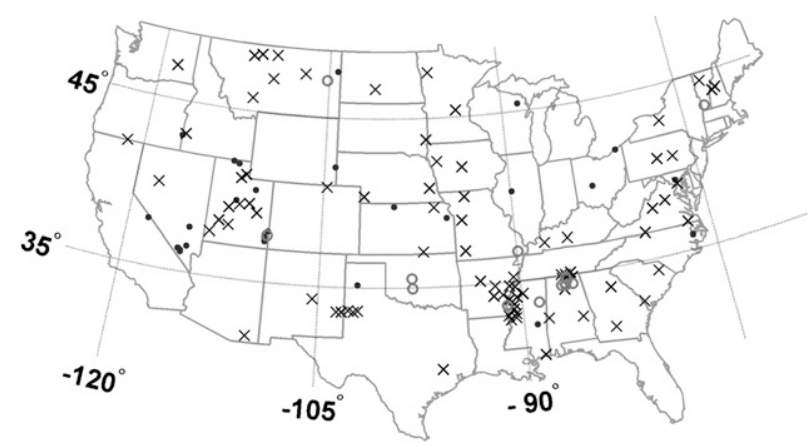

FIG. 1. Locations of SCAN soil moisture measurement sites that were (crosses) used for surface and root zone soil moisture validation (85 sites), (circles) used only for surface soil moisture validation (13 sites), and (dots) not used.

data, the SCAN observations were aggregated into pentad averages. Because of the quality control and the data requirements for the anomaly computation (appendix), only 98 SCAN sites could be used to assess the skill of surface soil moisture estimates, and only 85 of the 98 sites could be used to assess the skill of root zone moisture estimates. Liu et al. (2011) discuss the validity of using the single-profile (point-scale) SCAN measurements to assess the skill of land model estimates of soil moisture that represent average values across tiles or grid cells.

\section{3) STREAMFLOW OBSERVATIONS}

Streamflow gauge data for 18 basins in the United States, ranging in size from $1900 \mathrm{~km}^{2}$ to $1400000 \mathrm{~km}^{2}$, were used to assess runoff estimates [Table 1; see Koster et al. (2010) and Mahanama et al. (2012) for details]. The streamflow data were naturalized to account for anthropogenic impacts, including upstream regulation, water withdrawals, and evaporation from reservoir surfaces. Note that some of the basins used by Mahanama et al. (2012) lack sufficient observations during our study period and are thus not considered here.

\section{4) SNOW OBSERVATIOnS}

World Meteorological Organization (WMO) snow depth measurements were obtained from the National Climatic Data Center (Tedesco and Miller 2010). A total of 583 stations located in the Northern Hemisphere (mostly in Russia, Europe, and Alaska) for the period October 2002 through August 2009 were used because they fulfilled the screening criteria outlined in the appendix. In addition, we used the snow depth product from the Canadian Meteorological Centre (CMC) daily snow analysis (Brasnett 1999; Brown and Brasnett 2010). The $\mathrm{CMC}$ product provides daily snow depth throughout the Northern Hemisphere at a horizontal resolution of approximately $24 \mathrm{~km}$ for the period of March 1998 to the present. The CMC snow analysis is based on optimal interpolation of in situ daily snow depth observations and aviation reports with a first-guess field generated from a simple snow model driven by analyzed temperatures and forecast precipitation from the Canadian forecast model (Brasnett 1999). The CMC product is often considered the "best available" snow depth product for the Northern Hemisphere and has been used for evaluating model output (e.g., Su et al. 2010). Finally, Sturm et al. (2010) provide climatological snow density estimates as a function of snow depth, day of year, and snow class (except for the "ephemeral" snow class; see their Eq. 6). Using the snow class map shown in Sturm et al. (1995) we obtained SWE estimates by multiplying the CMC snow depths with the Sturm et al. (2010) snow densities for subsequent comparison against SWE estimates from MERRA and MERRA-Land.

\section{5) ERA-INTERIM}

Whenever possible, we compare the skill of MERRA and MERRA-Land to that of the European Centre for Medium-Range Weather Forecasts (ECMWF) Re-Analysis (ERA)-Interim (ERA-I), the most recent ECMWF reanalysis product (Dee et al. 2011; http://www.ecmwf.int/research/era). Here, we use the daily ERA-I data product that is publicly available at $1.5^{\circ}$ resolution from 1989 to present (updated with about two months latency). Soil moisture in ERA-I is modeled in four layers $(0-7,7-28,28-100$, and 100$289 \mathrm{~cm})$ and updated in response to screen-level $(2 \mathrm{~m})$ observations of air temperature and humidity. This soil moisture analysis, however, is designed to improve the turbulent surface flux estimates and subsequent atmospheric forecasts and provides no clear benefit to soil moisture estimates (Drusch and Viterbo 2007). ERA-I also includes a snow analysis based on in situ snow depth and satellite snow cover observations (Drusch et al. 2004). The structure functions used in the ERA-I snow depth analysis differ from those used in the CMC product. Because of recently discovered problems in the ECMWF system, the CMC structure functions have been adopted in the latest version of the ECMWF operational system (P. De Rosnay 2010, personal communication, ECMWF). Szczypta et al. (2011) provide a detailed assessment over France of surface meteorological forcing data from ERA-I (with and without corrections to monthly GPCP v2.1 precipitation estimates) and find that the precipitation corrections lead to improved root zone soil moisture estimates. 


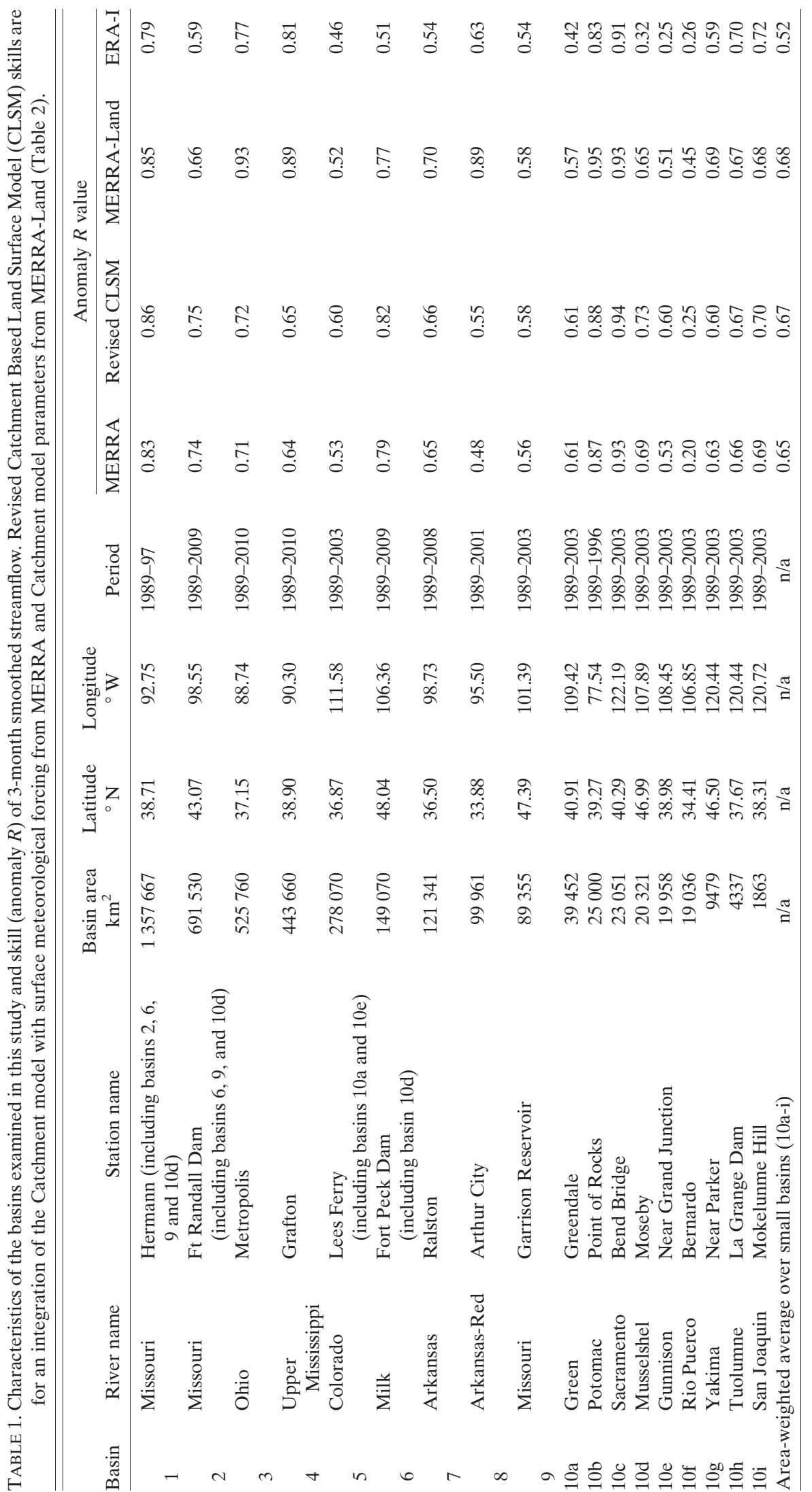



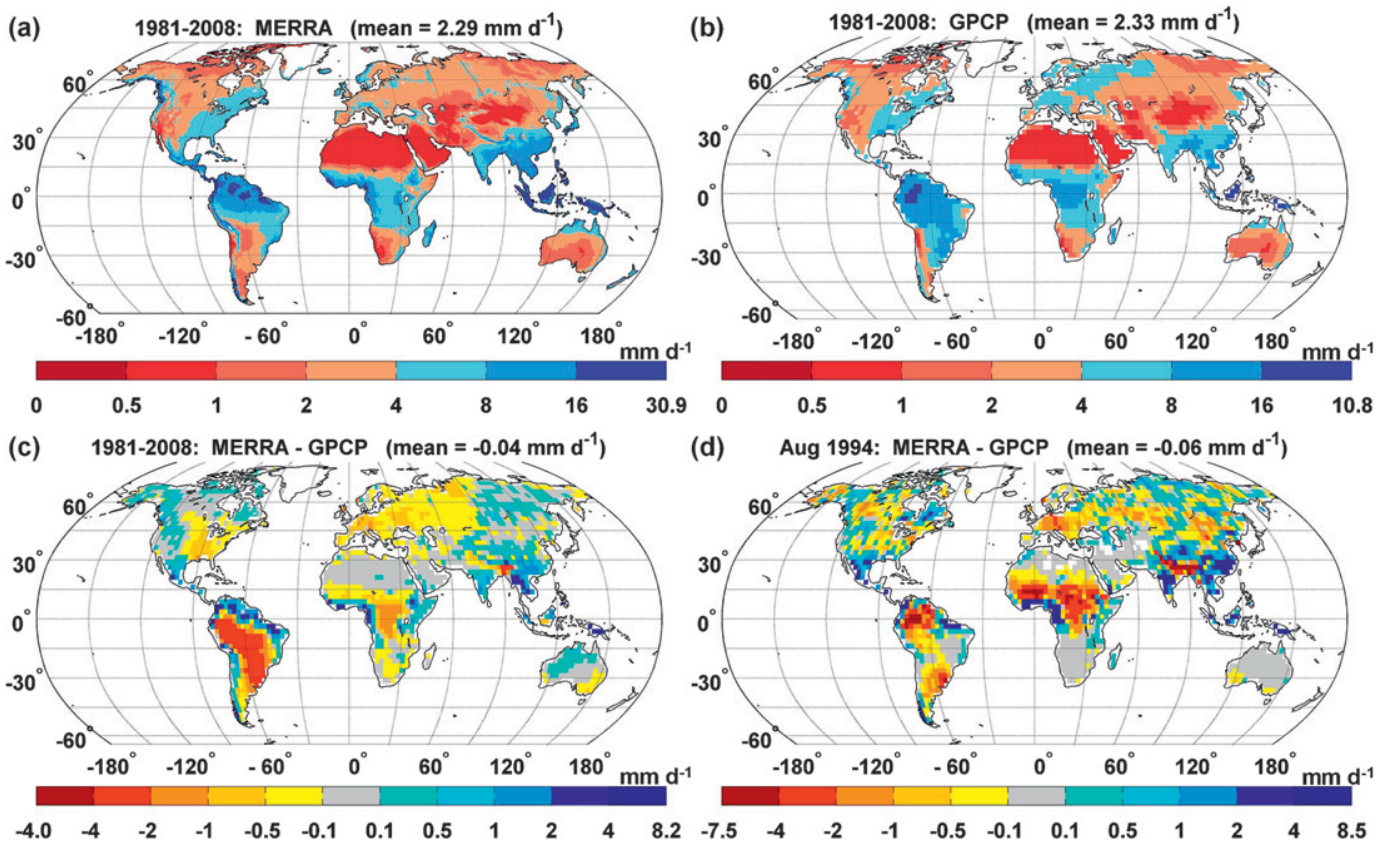

(d) Aug 1994: MERRA - GPCP (mean $=-0.06 \mathrm{~mm} \mathrm{~d}^{-1}$ )

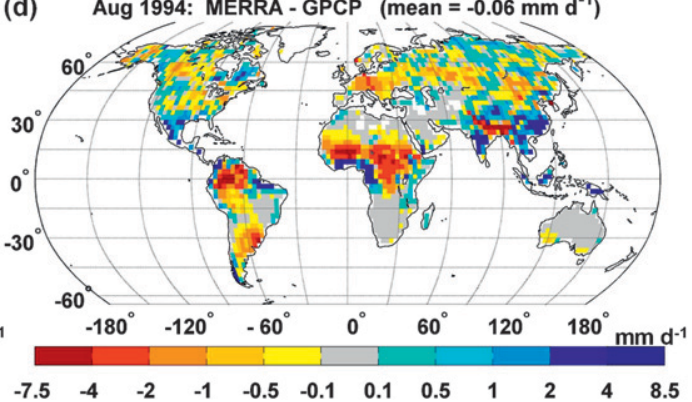

FIG. 2. Annual precipitation ( $\mathrm{mm} \mathrm{day}^{-1}$ ) averaged over the period 1981-2008 for (a) MERRA and (b) GPCP. Precipitation differences (MERRA minus GPCP in mm day ${ }^{-1}$ ) averaged over (c) 1981-2008 and (d) August 1994.

\section{Motivation for and construction of MERRA-Land}

\section{a. Motivation for a revised product}

Precipitation is by far the most important driver of a land surface hydrological simulation; hence precipitation error will have an overwhelming impact on the accuracy of simulated hydrological fields regardless of the accuracy of the other forcings or the realism of the underlying land model. Although the spatial distribution of the MERRA mean annual precipitation is quite good compared to that of other reanalysis products (Bosilovich et al. 2011, see their Fig. 3), two correctable deficiencies associated with MERRA's precipitation forcing motivate our construction here of a revised land product: 1) inaccuracies in the climatological and synoptic variability of the precipitation forcing, and 2) inaccuracies in the intensity and diurnal cycle of this forcing.

\section{1) LONG-TERM PRECIPITATION TOTALS}

The precipitation estimates generated by MERRA do not benefit from the assimilation of surface rain gauge data. While they do benefit from the assimilation of water vapor, wind fields, and other atmospheric quantities (Rienecker et al. 2011), the onset, intensity, and cessation of any rainfall event is chiefly controlled by the model's precipitation parameterizations. (The assimilation in MERRA of satellite rain rate retrievals over the ocean has a negligible impact on the system over land.) As a result, MERRA precipitation fields show some inaccuracies relative to established, observations-based datasets, particularly over land, as will be shown next.

Figure 2a shows the mean annual precipitation for the period 1981-2008 from MERRA, and Fig. 2b shows the corresponding observations-based estimates from GPCP (section 2b). MERRA and GPCP both have a global mean over land of around $2.3 \mathrm{~mm} \mathrm{day}^{-1}$ for 1981-2008 (see Bosilovich et al. 2011 for a discussion of the global water budget and trends of MERRA and other reanalysis products). To first order, the precipitation fields look similar, with MERRA locating deserts and rainy areas in the proper places and assigning, in most regions, approximately the correct magnitudes to the mean annual precipitation rates. The MERRA product, however, differs from the GPCP reference, as revealed by the difference map in Fig. 2c. MERRA mean annual precipitation rates are biased low in much of South America and central Africa and biased high in Southeast Asia, in Indonesia, and along the tropical South American and African coasts. Smaller but still significant biases appear across much of the globe. Note, however, that uncertainty in the GPCP precipitation estimates themselves, a strong function of rain gauge density, varies significantly across the globe (Adler et al. 2003).

Figure $2 \mathrm{~d}$ shows the difference field (MERRA minus GPCP) for a single representative month (August 1994). Relative to those found for the long-term mean, the errors for this month are reduced in parts of South America 

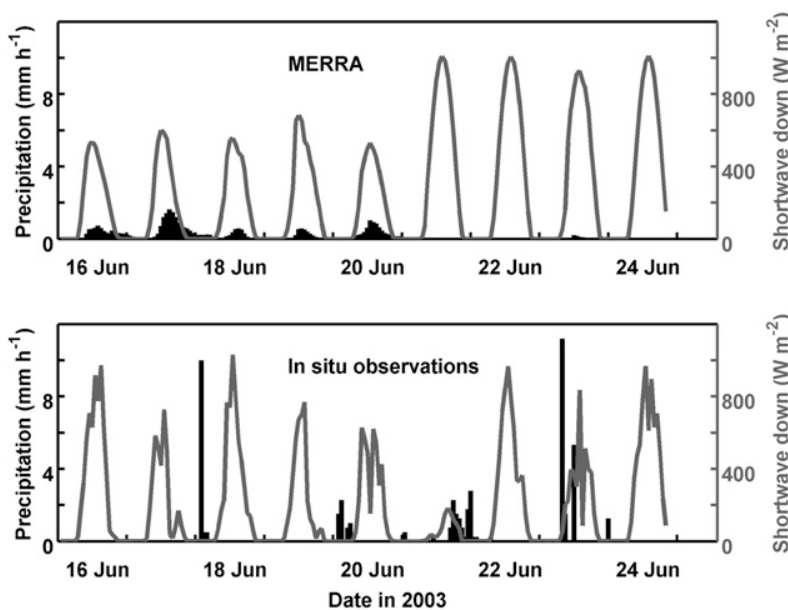

FIG. 3. (Gray lines) Downward shortwave radiation and (black bars) precipitation from (top) MERRA for a grid cell near Gainesville, Florida (centered at $30^{\circ} \mathrm{N}, 82^{\circ} \mathrm{W}$ ), and (bottom) in situ observations taken at the US-SP3 FLUXNET site $\left(29.75^{\circ} \mathrm{N}\right.$, $82.16^{\circ} \mathrm{W}$ ) located within the grid cell.

but are more often magnified, with values exceeding $1 \mathrm{~mm}$ day $^{-1}$ in many midlatitude regions. Such errors will have a first-order impact on the simulated land surface hydrological variables. Our assumption in this paper is that "correcting" the MERRA precipitation forcing so that it agrees with the GPCP data as much as possible should lead to improved hydrological simulation.

\section{2) INTENSITY AND DIURNAL CYCLE OF PRECIPITATION}

Errors in the intensity and the diurnal cycle of precipitation are common in many atmospheric modeling systems (Dai 2006). Unsurprisingly, MERRA also suffers from such deficiencies. Figure 3 illustrates this with a representative example. The top panel shows MERRA time series of solar radiation and precipitation for a 9-day summer period at a single grid cell near Gainesville, Florida. The bottom panel shows the corresponding observations from a flux network (FLUXNET) site located within the MERRA grid cell. The MERRA time series differ from the FLUXNET time series in at least three fundamental ways, each directly relevant to the simulation of hydrological fluxes at the land surface. First, despite being similar in long-term average, MERRA precipitation rates are less intense; relative to observations, MERRA rain tends to come down as more of a long-lasting "drizzle." Second, the precipitation in MERRA tends to be highest in the middle of the day, whereas the observations show frequent nighttime rain maxima. Third, in the observations, a daytime precipitation event tends to reduce incoming solar radiation substantially (e.g., on 21 June 2003), whereas in MERRA, the rain reduces the solar radiation by only about half (16-20 June 2003) or sometimes hardly at all (23 June 2003).

The discrepancy between the distributed (grid cell) scale of the MERRA estimates $(\sim 50 \mathrm{~km})$ and the point scale of the in situ observations may be responsible for at least part of the rain intensity and radiation differences shown in Fig. 3. Nevertheless, regardless of their source, the three features of MERRA rain and radiation behavior highlighted in the figure are commonplace for MERRA summer precipitation and work together to confound the ability of MERRA to provide adequate amounts of rainwater to the soil. Simply put, the drizzle of MERRA rainfall during daylight hours-hours for which plenty of simulated solar radiation energy is available for evaporation-leads to the immediate evaporation of much of this rainfall directly from droplets sitting on the surface of the vegetation canopy (i.e., directly from the land model's interception reservoir). As a result, not enough of the water is allowed to drip down through the canopy and ultimately infiltrate the soil or generate surface runoff. Relative to an offline simulation with the same land model but with more realistic forcing (e.g., along the lines of that shown for the FLUXNET site), MERRA produces soil moistures that are too dry (section 4b), with consequent impacts on the simulation of land surface hydrological fluxes.

\section{b. Construction of the MERRA-Land data product}

To mitigate the impacts of these problems, MERRALand estimates were generated by replaying (i.e., running offline with prescribed and improved meteorological forcing) a revised version of the land component of the MERRA system.

\section{1) Precipitation CORRections}

For the new MERRA-Land product, all atmospheric forcing fields (including air temperature and humidity, radiation, wind speed, and surface pressure) for the land surface model were taken directly from hourly MERRA output, with one important exception: the MERRA precipitation forcings were corrected toward gauge- and satellite-based observations using the GPCP version 2.1 pentad product (section $2 \mathrm{~b}$ ). Because of their coarse (pentad) time resolution, the GPCP data themselves cannot be used to force the Catchment model. We therefore use the GPCP estimates to construct a corrected version of the MERRA precipitation. The approach used here is similar in concept to that applied in the Global Soil Wetness Project (Dirmeyer et al. 2006) and other global land modeling studies (Berg et al. 2005; Guo et al. 2006; Qian et al. 2006; Sheffield et al. 2006). Based on results from these earlier studies, we recognize that corrections to surface radiation and surface air temperature have 
TABLE 2. Catchment land surface model parameter changes between MERRA and the revised Catchment model used in MERRA-Land. SATCAP is computed as a fraction of leaf area index (LAI).

\begin{tabular}{|c|c|c|c|c|}
\hline Parameter & Description & Units & MERRA & MERRA-Land \\
\hline SATCAP & Capacity of canopy interception reservoir & $\mathrm{kg} \mathrm{m}^{-2}$ & 1.0LAI & $0.2 \mathrm{LAI}$ \\
\hline FWETL & $\begin{array}{l}\text { Areal fraction of canopy leaves onto which } \\
\text { large-scale precipitation falls }\end{array}$ & Dimensionless & 1.0 & 0.02 \\
\hline FWETC & $\begin{array}{l}\text { Areal fraction of canopy leaves onto which } \\
\text { convective precipitation falls }\end{array}$ & Dimensionless & 0.2 & 0.02 \\
\hline WEMIN & Minimum SWE in snow-covered area fraction & $\mathrm{kg} \mathrm{m}^{-2}$ & 13 & 26 \\
\hline DZ1MAX & Maximum depth of uppermost snow layer & $\mathrm{m}$ & 0.05 & 0.08 \\
\hline
\end{tabular}

a much smaller effect than precipitation corrections. Such additional forcing corrections could in any case lead to inconsistencies across the forcing fields in cases where the observational data may be contradictory. Consequently, we restrict ourselves here to correcting the precipitation forcing.

The corrected MERRA precipitation forcings were obtained as follows. First, the hourly MERRA total precipitation was time averaged and regridded to the scale of the correcting GPCP dataset (i.e., to pentad and $2.5^{\circ}$ resolution). Next, for each pentad of each year and for each $2.5^{\circ}$ grid cell, a scaling factor was computed by determining the ratio of the GPCP estimate to the standard MERRA data (i.e., on the grid and at the time scale of the correcting observations). Finally, these scaling factors were regridded back to the MERRA grid and applied to the MERRA data - a scaling factor derived for a given grid cell and year/ pentad was applied to the MERRA precipitation rates (large-scale precipitation, convective precipitation, and snowfall separately) in each of the 120 hourly time steps within that pentad. If for a given grid cell the aggregated MERRA value was zero, the corresponding corrected MERRA precipitation values were set to zero, even if the correcting observations indicated nonzero precipitation (rather than distributing the observed precipitation across time steps in an ad hoc way) to maintain consistency across the forcing variables (including surface radiation) to the fullest extent possible. By construction, the corrected MERRA precipitation is nearly identical to the GPCP estimates at the pentad and $2.5^{\circ}$ resolution and is therefore not shown.

Because the GPCP product is based on precipitation observations from satellites and/or gauges well beyond the data used in the MERRA atmospheric assimilation, we expect that the GPCP-corrected MERRA precipitation forcing is more accurate than the standard MERRA precipitation product. Note again, however, that the (hourly, $0.5^{\circ}$ ) corrected precipitation dataset is a scaled version of the MERRA precipitation forcing, rather than the original (pentad, $2.5^{\circ}$ ) GPCP dataset. The diurnal cycle, the frequency and relative intensity of rainfall events at the subpentad scale, and the sub- $2.5^{\circ}$ spatial variations are entirely based on MERRA estimates. While Qian et al. (2006) discuss the possibility of also adjusting the diurnal cycle of the precipitation, we choose here to impose the subpentad variations of the original MERRA precipitation to maintain maximum consistency across the forcing variables (including surface radiation). Finally, note again that the precipitation corrections are constructed separately for each pentad of each year and thus go beyond a climatological adjustment.

\section{2) CATCHMENT MODEL PARAMETER REVISIONS}

The Catchment model version and model parameters used for MERRA-Land are identical to those used for MERRA data production except for the changes to the interception and snow parameters listed in Table 2. These changes bring the Catchment model used for MERRALand up to date with the forthcoming version used in the GEOS-5 experimental NWP and seasonal forecasting systems. Of particular relevance to the MERRA-Land product are the changes made to the rainfall interception parameters FWETL and FWETC, changes that mitigate the impact of the discrepancies outlined in Fig. 3. These two parameters describe the fractional areas over which large-scale and convective rainfall, respectively, are applied to the canopy interception reservoir. In MERRA, large-scale rainfall is applied uniformly to the canopy (FWETL $=1)$, whereas the intensity of convective rainfall at a given time step is quintupled and applied to $1 / 5$ th of the area of the canopy $($ FWETC $=0.2)$ water is conserved, but the greater local depth allows it (in principle) to overflow the interception reservoir and drip down to the surface more easily. In MERRA-Land, this effect is heightened considerably-the intensity of either form of rainfall is multiplied by 50 and applied to $1 / 50$ of the canopy area $($ FWETL $=$ FWETC $=0.02)$. We emphasize that this change is not meant to represent a realistic treatment of subgrid rainfall variability. It is designed solely to circumvent known deficiencies in the atmospheric model's representation of the intensity and diurnal cycle of rainfall and contemporaneous radiation 
(a)

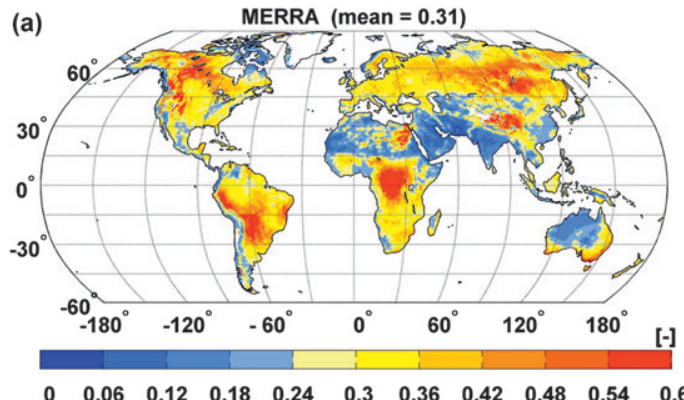

(c)

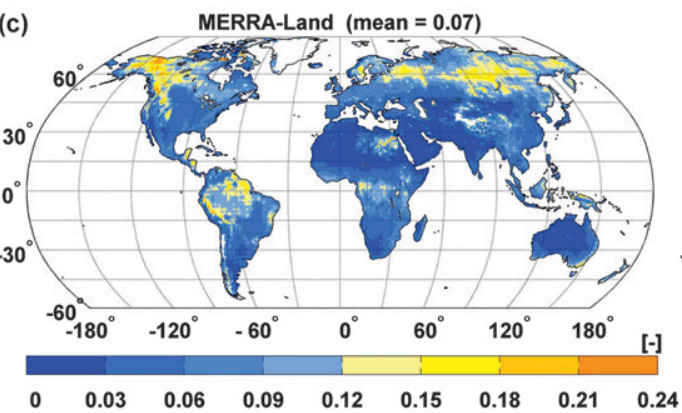

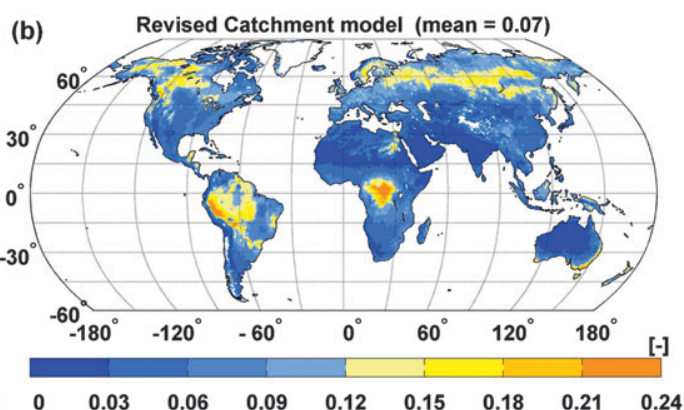

(d)

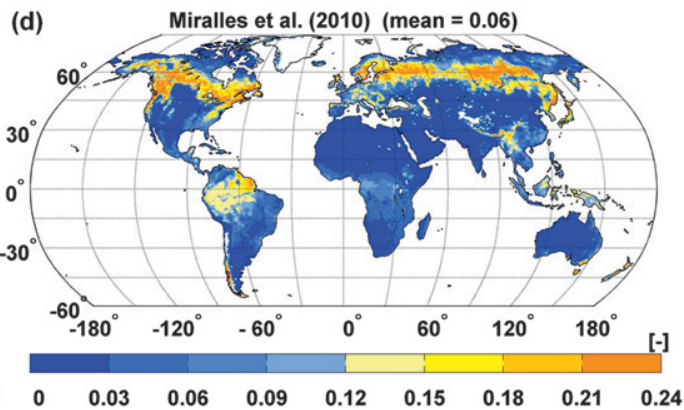

FIG. 4. 2003-07 average interception loss fraction (dimensionless) from (a) MERRA, (b) revised Catchment model with MERRA forcing, (c) MERRA-Land, and (d) observation-based estimates from Miralles et al. (2010). Note the different colorbar in (a).

(Fig. 3). The smaller fractional area of rainfall, while not realistic, does allow more of the rainfall to drain through the canopy and reach the soil, leading to wetter soil and much more sensible interception loss fractions (section 4a). It has no other impact on the simulation-in particular, the prescribed $1 / 50$ th of the canopy area does not affect the partitioning of throughfall into runoff and infiltration at the soil surface. Note that in other offline applications with the Catchment model, applications involving atmospheric forcing without the noted problems, we can safely revert to the MERRA values for the two parameters.

Table 2 lists additional changes to the model parameters that bring the Catchment model up-to-date with the forthcoming GEOS-5 version. The change in the capacity of the interception reservoir (SATCAP) has an effect similar to that of the changes to FWETL and FWETC (albeit much smaller, given the nonlinear dynamics of the interception model). Moreover, changes were made to the minimum SWE in the snow-covered area fraction (WEMIN) and the maximum depth of the uppermost snow layer (DZ1MAX) to improve the modeled albedo and the stability of the surface calculation when snow is present (not shown here). Because in the offline replay configuration of MERRA-Land the land fluxes do not feed back on the atmosphere, the snow parameter changes lead to only minor differences between MERRA-Land and MERRA.

\section{Results}

In this section we evaluate land surface states and fluxes from MERRA and MERRA-Land against a variety of observations and independent model estimates. Our evaluation includes interception loss fraction and latent heat flux (section 4a), soil moisture (section $4 \mathrm{~b}$ ), runoff (section 4c), and snow (section 4d). Where appropriate, we also provide skill estimates for ERA-I (section $2 b$ ). We refer the reader to Yi et al. (2011) for a discussion of MERRA surface air temperature, vapor pressure deficit, and incident solar radiation. Yi et al. (2011) also provide additional analysis of MERRA surface soil moisture. Moreover, Decker et al. (2011) evaluate MERRA land surface forcings and fluxes against tower observations.

\section{a. Interception loss fraction and latent heat flux}

As discussed in section 2, the character of MERRA precipitation and radiation forcing is expected to have a detrimental effect on land surface hydrology. Perhaps the most striking effect is seen in the interception loss fraction $I$, defined as the fraction of incoming rainfall that is intercepted by the canopy and reevaporated back to the atmosphere without ever infiltrating the soil or contributing to surface runoff. MERRA's long-term average $I$ values, shown in Fig. $4 \mathrm{a}$, are greater than 0.24 almost everywhere, even in nonforested areas (e.g., the U.S. Great 
Plains) and occasionally in very sparsely vegetated areas (e.g., the Sahara, and western and central Australia). In tropical rain forests, $I$ values can exceed 0.5 . Globally averaged, MERRA's interception loss fraction is $I=$ 0.31 . These fractions are far in excess of published estimates, such as those of Miralles et al. (2010), shown in Fig. $4 \mathrm{~d}$. The latter were derived by calibrating a global model of interception dynamics to a large number of in situ observations (see references in Miralles et al. 2010). In their model, the largest $I$ values, ranging from $I=0.15$ to $I=0.24$, are found in the boreal forests of North America, Scandinavia, and Russia. Somewhat smaller values of $I=0.06$ to $I=0.15$ are found in tropical rain forests (including Indonesia and the Amazon and Congo basins) and midlatitude forested regions (eastern United States, parts of Europe). Globally averaged, Miralles et al. (2010) estimate $I=0.06$. For comparison, Sakaguchi and Zeng (2009) report $I=0.12$ for the Community Land Model version 3.5.

Figure $4 \mathrm{~b}$ shows the interception loss fractions for the revised Catchment model (Table 2, section 4b) when forced with MERRA surface meteorology. The revised interception parameters lead to much more realistic $I$ values, with a global average of $I=0.07$. In the boreal forest, the revised Catchment model now underestimates the interception loss fraction (relative to the Miralles et al. (2010) estimates), with values ranging between $I=$ 0.09 and $I=0.21$. In nonforested areas and deserts, the interception loss fraction is now typically below $I=0.09$. However, errors in the long-term climatology of MERRA precipitation still lead to $I$ values greater than $I=0.21$ in the Amazon and Congo basins. When the revised Catchment model is forced with the GPCP-corrected precipitation (i.e., MERRA-Land, shown in Fig. 4c) the $I$ values for these two basins are reduced and agree well with the estimates from Miralles et al. (2010). Globally averaged, the MERRA-Land interception loss fraction is $I=0.07$. The largest remaining differences between $I$ values from MERRA-Land and Miralles et al. (2010) are in the boreal forests, where MERRA-Land estimates are lower.

The revised treatment of interception loss in MERRALand, combined with the GPCP-based improvements in precipitation forcing, has impacts on other hydrological fields. Figure 5 shows an example as follows: MERRA estimates of latent heat flux (LH) for August 1994 are shown in Fig. 5a, and those for MERRA-Land are shown in Fig. 5b. For reference, Fig. 5c shows an estimate based on 12 different products using a variety of data sources from remote sensing, flux tower measurements, and land surface modeling (Jimenez et al. 2011). (MERRA is one of the 12 estimates in the multiproduct average.) Overall, the three estimates agree reasonably well, with global
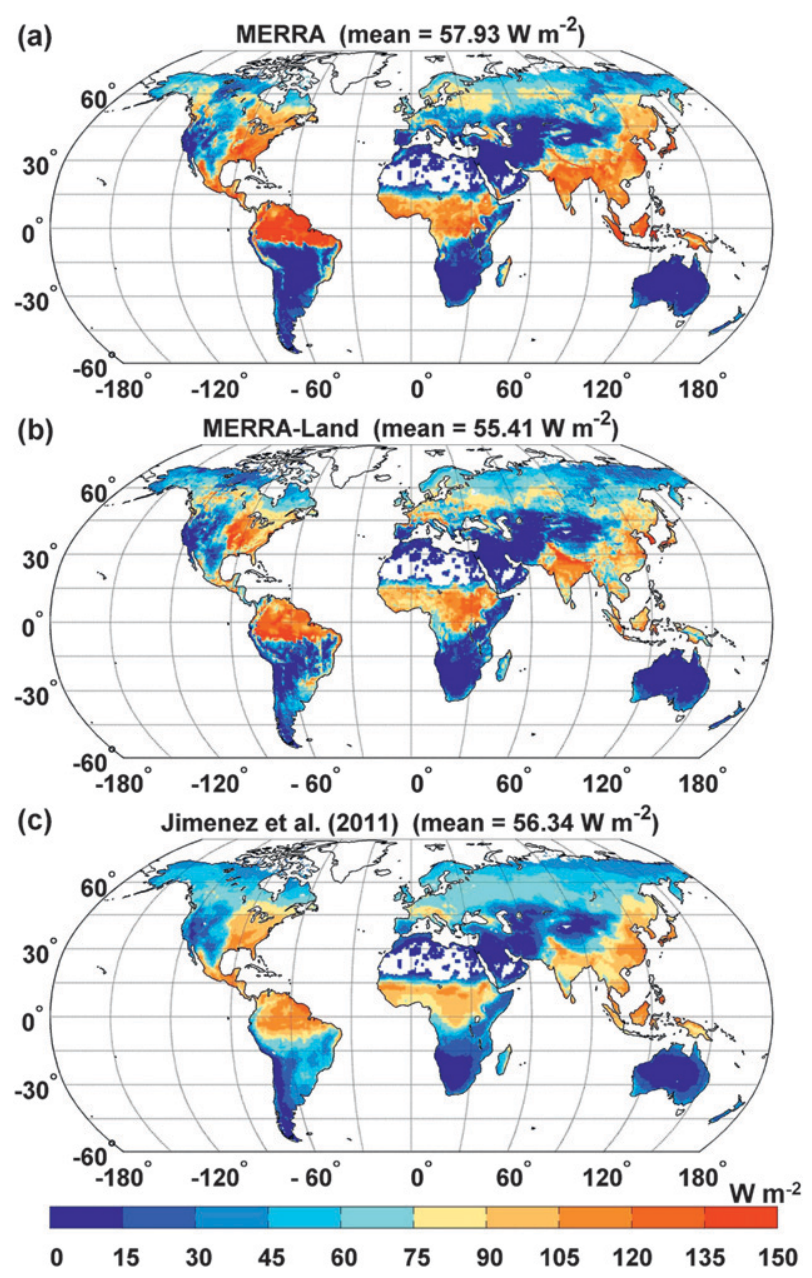

FIG. 5. Average latent heat flux $\left(\mathrm{W} \mathrm{m}^{-2}\right)$ for August 1994 from (a) MERRA, (b) MERRA-Land, and (c) the Jimenez et al. (2011) multiproduct average.

average LH values for this month of 58.0 (MERRA), 55.4 (MERRA-Land), and $56.3 \mathrm{~W} \mathrm{~m}^{-2}$ (multiproduct average). The three estimates also agree in the broad global pattern of LH, with high values in the eastern United States, the tropical rain forests, and Southeast Asia. Low values in the Southern Hemisphere are due to winter conditions in August.

One important difference between MERRA and the multiproduct average LH, however, appears in the Amazon basin. MERRA LH exhibits an extremely sharp north-south gradient, with values quickly dropping from around $140 \mathrm{~W} \mathrm{~m}^{-2}$ north of $5^{\circ} \mathrm{S}$ to less than $20 \mathrm{~W} \mathrm{~m}^{-2}$ south of $8^{\circ} \mathrm{S}$. The corresponding gradient in the multiproduct average LH is much less steep, with values dropping from $100 \mathrm{~W} \mathrm{~m}^{-2}$ north of $7^{\circ} \mathrm{S}$ to $60 \mathrm{~W} \mathrm{~m}^{-2}$ south of $15^{\circ} \mathrm{S}$. Whereas MERRA could be considered an outlier among the products evaluated by Jimenez et al. (2011), MERRA-Land is not-its LH estimates lie within the 

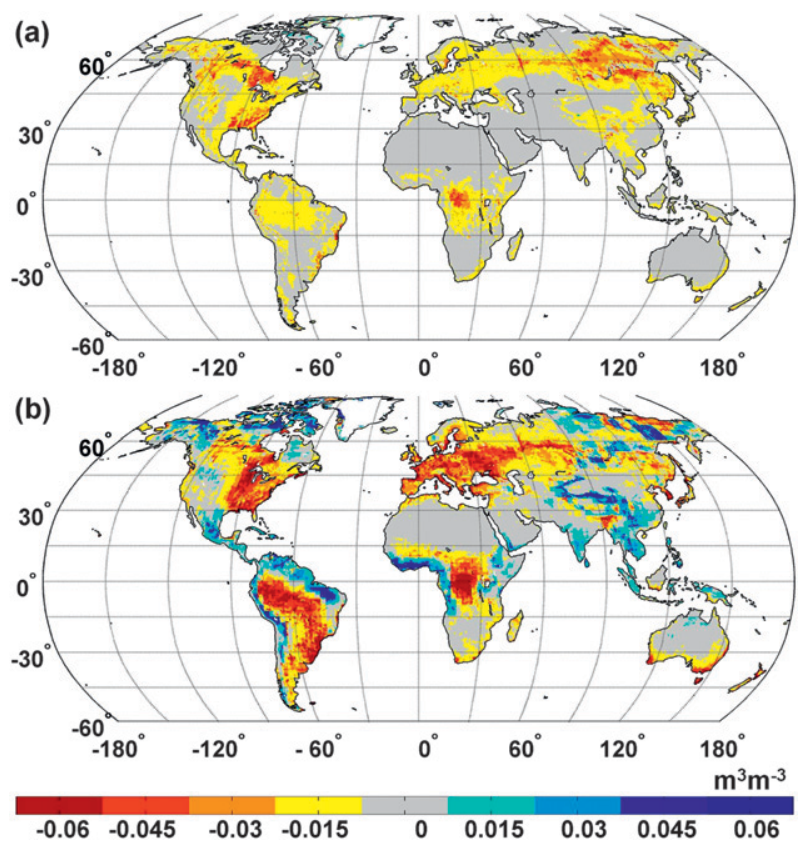

FIG. 6. Annual average root zone soil moisture $\left(\mathrm{m}^{3} \mathrm{~m}^{-3}\right)$ differences (1981-2008): (a) MERRA minus revised Catchment model forced with MERRA surface meteorology, and (b) MERRA minus MERRA-Land.

range of estimates contributing to the multiproduct average (not shown, see their Fig. 6). Note that MERRA precipitation errors also exhibit a strong gradient along $5^{\circ} \mathrm{S}$ (Fig. 2d). Additional analysis (not shown) indicates that the GPCP-based precipitation corrections and the interception parameter revisions contribute about equally to the LH improvements in MERRA-Land.

\section{b. Soil moisture}

The interception model revisions by themselves have important implications for soil moisture. Again, the revised parameters were designed to let more of the incoming rainfall reach the soil and thereby increase long-term soil moisture levels. This can be seen in Fig. 6a, which shows the difference between the 1981-2008 average root zone soil moisture from MERRA and from the revised Catchment model (when forced with MERRA surface meteorology). Differences in root zone soil moisture up to $-0.05 \mathrm{~m}^{3} \mathrm{~m}^{-3}$ occur in the boreal forests, the southeastern United States, and the Amazon and Congo basins, that is, in areas with generally moist climates and with the largest changes in the interception loss fraction (Fig. 4). As expected, soil moisture generated by the revised Catchment model is always wetter than that of MERRA.

Figure $6 \mathrm{~b}$ shows the combined impact of the GPCPbased precipitation corrections and the Catchment model parameter revisions on long-term root zone soil moisture in MERRA-Land. Unsurprisingly, the overall global pattern

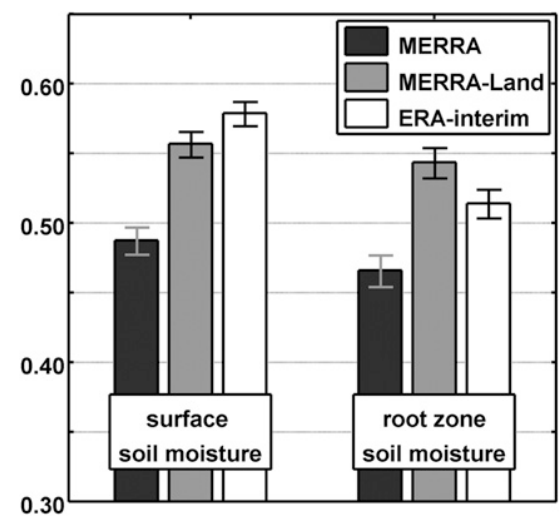

FIG. 7. Skill (pentad anomaly $R$; dimensionless) of MERRA, MERRA-Land, and ERA-I estimates (2002-09) vs SCAN in situ surface and root zone soil moisture measurements. Error bars indicate approximate $95 \%$ confidence intervals.

of the root zone soil moisture differences is dominated by the differences in the precipitation forcing. Where MERRA precipitation is biased dry against GPCP (Fig. 2c), such as in much of South America and central Africa, MERRA-Land root zone soil moisture is considerably higher because of the combined effect of higher precipitation forcing and reduced interception (Fig. 6b). Where MERRA precipitation is biased wet, the reduced precipitation forcing in MERRA-Land counteracts the reduced interception loss, typically resulting in somewhat drier or unchanged root zone soil moisture conditions in MERRA-Land (for example in Southeast Asia, in Indonesia, along the tropical South American and African coasts, and in northern Australia).

To address the relative realism of the MERRA and MERRA-Land soil moisture estimates, we now validate them against in situ observations taken between 2002 and 2009 in the continental United States (Fig. 1, section 2b). Our analysis focuses on skill in terms of the anomaly time series correlation coefficient $R$ (appendix). Figure 7 shows that for MERRA estimates, the average anomaly skill at pentad time scales is $R=0.49$ for surface soil moisture (across 98 sites) and $R=0.47$ for root zone soil moisture (across 85 sites). For MERRA-Land, the anomaly $R$ values increase to $R=0.56$ for surface and $R=0.54$ for root zone soil moisture, a net gain of $\Delta R \sim$ 0.07 over the MERRA $R$ values. Approximate $95 \%$ confidence intervals, also shown in Fig. 7, are $\Delta R \leq \pm 0.01$ (appendix). The improvements in the MERRA-Land estimates are therefore statistically significant.

For comparison, Fig. 7 also shows the skill of ERA-I soil moisture estimates (section 2b). ERA-I skill is $R=$ 0.58 for surface and $R=0.51$ for root zone soil moisture. Like MERRA-Land, ERA-I is significantly more skillful than MERRA, but ERA-I does not perform quite as 


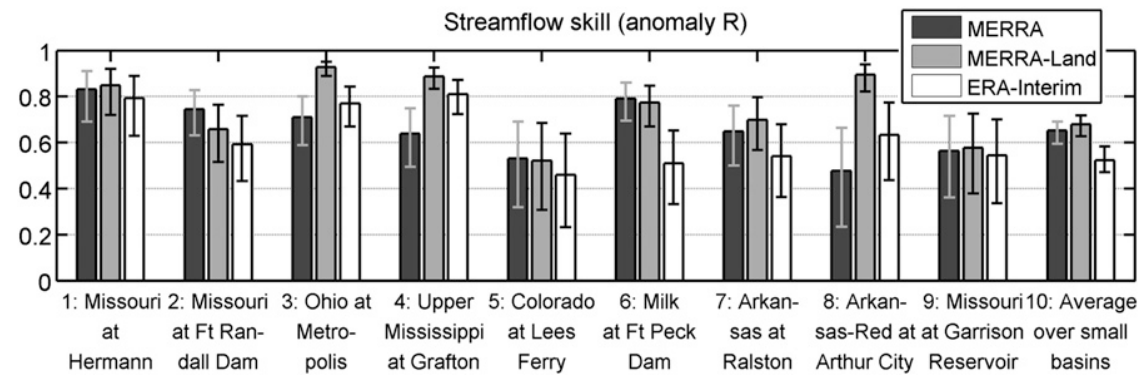

FIG. 8. Seasonal anomaly time series correlation coefficients (dimensionless) for runoff estimates from MERRA, MERRA-Land, and ERA-I for the basins and time periods listed in Table 1.

well as MERRA-Land for root zone soil moisture. The ERA-I skill for surface soil moisture is higher than that of MERRA-Land, presumably because the surface layer depth $(0-7 \mathrm{~cm})$ of ERA-I better matches the in situ sensing depth $(5 \mathrm{~cm})$; MERRA and MERRA-Land use a much shallower $(0-2 \mathrm{~cm})$ surface layer. Additional analysis (not shown) reveals that most of the improvements in soil moisture skill from MERRA to MERRA-Land can be attributed to the GPCP-based precipitation corrections. The soil moisture skill (in terms of anomaly $R$ ) is only weakly sensitive to the changes in the canopy interception parameters of the land model.

\section{c. Runoff}

We used naturalized streamflow measurements taken between 1989 and 2009 for 18 basins in the United States (Table 1, section $2 b$ ) to evaluate runoff estimates. Figure 8 summarizes the skill (anomaly $R$ ) at seasonal time scales (appendix) for the 9 larger basins and the (areaweighted) average for the 9 smaller basins with areas less than $40000 \mathrm{~km}^{2}$ (Table 1). Skill values for MERRA runoff in the larger basins range from $R=0.48$ for the Arkansas-Red at Arthur City to $R=0.83$ for the Missouri at Hermann. Because of the 3-month smoothing used here (appendix) and because there are typically only $15 \mathrm{yr}$ of overlap between the streamflow observations and the reanalysis runoff estimates (Table 1), the $95 \%$ confidence intervals for the $R$ values are large (between $\Delta R \sim \pm 0.1$ and $\Delta R \sim \pm 0.2$ for individual basins). MERRA and MERRA-Land, in general, have comparable skill, with three exceptions: MERRA-Land skill is significantly higher than MERRA skill for the Ohio at Metropolis, the Upper Mississippi at Grafton, and the Arkansas-Red at Arthur City.

Figure 8 also shows that the skill values for ERA-I are typically lower than those of MERRA and MERRALand except for the Ohio at Metropolis, the Upper Mississippi at Grafton, and the Arkansas-Red at Arthur City where ERA-I skill is between that of MERRA and
MERRA-Land. ERA-I skill is significantly worse than that of the other estimates for the Milk at Fort Peck Dam and for the average over the 9 small basins. The lower skill of ERA-I is most likely due to the coarser $\left(\sim 1.5^{\circ}\right)$ horizontal resolution of the publicly available ERA-I estimates.

The revisions to the Catchment model parameters have a small but almost always positive impact. Table 1 shows that in all basins except one small watershed (Yakima near Parker) the $R$ values for the revised Catchment model forced with MERRA surface meteorological data are larger than those of MERRA. While the improvements are not statistically significant, the fact that they occur in so many basins is suggestive of improved hydrological simulation resulting from the improved canopy throughfall rates. However, the significant improvements in MERRALand over MERRA noted above are dominated by the positive impact of the GPCP-based precipitation corrections.

\section{d. Snow}

We first evaluate the skill of MERRA and MERRALand snow depth estimates against in situ measurements taken between 2002 and 2009 at 583 WMO stations in the Northern Hemisphere (section 2b). The station-average skill (pentad anomaly $R$; see the appendix) of snow depth estimates is $R=0.56$ for MERRA and $R=0.59$ for MERRA-Land (Table 3). While modest, the skill increase for MERRA-Land is nevertheless statistically significant. An approximate $95 \%$ confidence interval for the station-average $R$ value is less than $\Delta R \leq \pm 0.01$ (see appendix for details).

Errors in modeled snow depth estimates can be caused by errors in the land surface forcing data and by errors in the modeling of snow density. The snow depth bias error is $-1.0 \mathrm{~cm}$ for MERRA and $+5.8 \mathrm{~cm}$ for MERRALand when averaged over the WMO stations (Table 3). Similarly, station-average snow depth RMSE is $20.1 \mathrm{~cm}$ for MERRA and $24.3 \mathrm{~cm}$ for MERRA-Land (Table 3). 
TABLE 3. Skill summary for snow estimates. Anomaly $R$ values vs WMO measurements at 583 stations are provided with approximate 95\% confidence intervals. Skill vs CMC is area-weighted average over Northern Hemisphere grid cells (Fig. 9a,b).

\begin{tabular}{|c|c|c|c|c|c|}
\hline \multirow[b]{2}{*}{ Metric } & \multirow[b]{2}{*}{ Units } & \multirow[b]{2}{*}{ Dataset } & \multicolumn{2}{|c|}{ Snow depth } & \multirow{2}{*}{$\frac{\text { SWE }}{\text { vs CMC }+ \text { Sturm et al. (2010) }}$} \\
\hline & & & vs WMO & vs $\mathrm{CMC}$ & \\
\hline \multirow[t]{3}{*}{ Anomaly $R$} & Dimensionless & MERRA & $0.56 \pm 0.01$ & 0.51 & 0.49 \\
\hline & & MERRA-Land & $0.59 \pm 0.01$ & 0.50 & 0.49 \\
\hline & & ERA-I & $0.60 \pm 0.01$ & 0.39 & 0.38 \\
\hline \multirow[t]{3}{*}{ Bias } & $\mathrm{cm}$ & MERRA & -1.0 & -2.3 & -1.2 \\
\hline & & MERRA-Land & 5.8 & -0.2 & -0.6 \\
\hline & & ERA-I & 5.2 & 1.7 & 0.2 \\
\hline \multirow[t]{3}{*}{ RMSE } & $\mathrm{cm}$ & MERRA & 20.1 & 9.5 & 3.7 \\
\hline & & MERRA-Land & 24.3 & 12.0 & 4.4 \\
\hline & & ERA-I & 25.7 & 15.0 & 5.5 \\
\hline
\end{tabular}

The changes in bias and RMSE (and anomaly $R$ ) between MERRA and MERRA-Land are primarily due to the GPCP-based precipitation corrections and are not related to the snow parameter changes (not shown). The snow depth bias may be higher in MERRA-Land because the precipitation gauge undercatch may have been overcorrected in the GPCP precipitation in northern high latitudes (Swenson 2010). A potential bias in the WMO snow depth observations, however, offers another explanation. Most WMO snow depth observations are collected in open areas (such as airports) that are subject to wind-blown snow redistribution. Snow at WMO stations thus tends to be shallower and melt earlier than in surrounding terrain (Brown et al. 2003), which would imply a negative bias in the WMO measurements (relative to the larger-scale conditions).

Additional insights can be gained by comparing the MERRA and MERRA-Land snow fields against the $\mathrm{CMC}$ snow analysis (section $2 \mathrm{~b}$ ). The $\mathrm{CMC}$ product provides a spatially complete estimate of daily Northern Hemisphere snow depths, conditioned on in situ measurements and aviation reports. Figure 9a maps the skill (pentad anomaly $R$ ) of MERRA-Land snow depth versus the CMC product for the period from September 1998 to September 2009. The highest skill values are generally found in southern Siberia and across large portions of Canada and the United States, whereas lower skills are typically found in northern Siberia, the Tibetan Plateau, the Canadian Arctic, and in portions of Alaska. For reference, Fig. 9c shows the spatial density of in situ snow depth observations that contribute to the CMC snow analysis, based on all stations that were used at least once across the study period. Since only a fraction of these stations are typically used in any given daily analysis, the density map can be thought of as an upper limit.

A comparison of Figs. 9a and 9c shows that MERRALand and CMC snow depth estimates tend to disagree most when the CMC data are based on very few in situ snow depth observations (e.g., the high northern latitudes and the Tibetan Plateau). That is, the regions of low or even negative correlation coincide with areas where actual snow depths are largely unknown. Figure $9 \mathrm{c}$ also resembles the density of precipitation gauges used for conditioning the GPCP estimates and that of the radiosonde observations available for assimilation into MERRA (not shown). This implies that MERRA-Land (and MERRA)

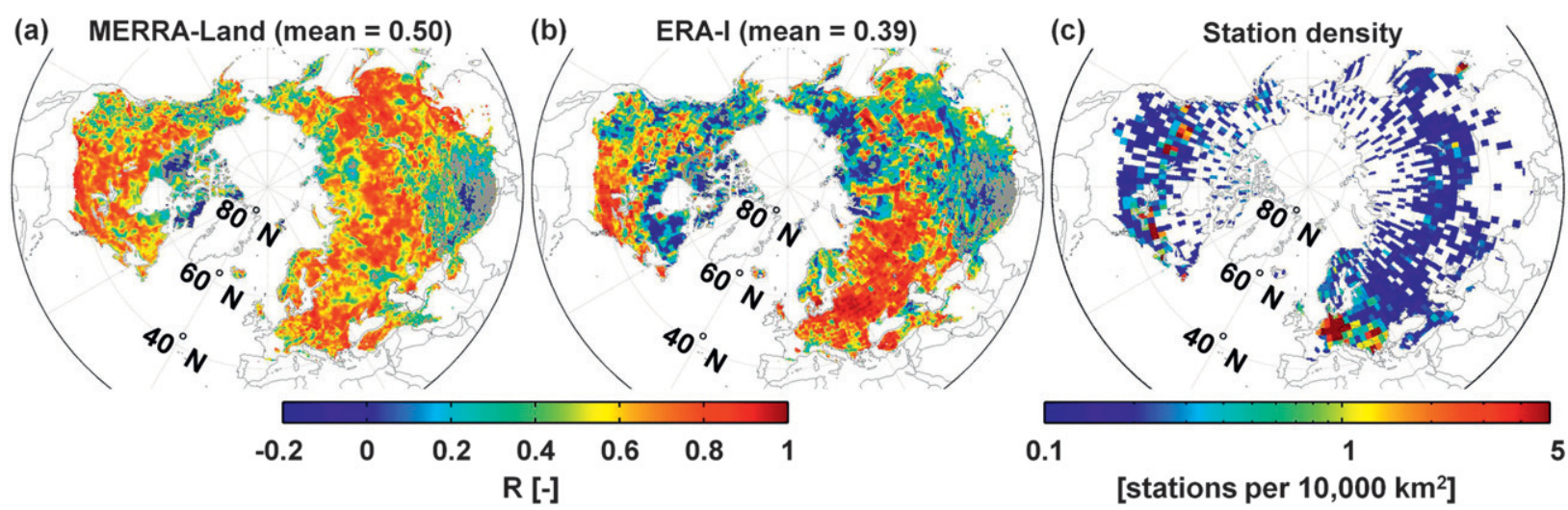

FIG. 9. Skill (pentad anomaly $R$ ) of (a) MERRA-Land and (b) ERA-I snow depth vs CMC estimates (September 1998-September 2009). Here, $R$ values that are not statistically different from zero at the $5 \%$ significance level are shown in gray. (c) Maximum density of in situ snow depth measurements available for CMC snow analysis. 
estimates are based on fewer conventional observations and are thus likely less accurate wherever CMC snow depths are less accurate.

The geographic skill pattern for MERRA snow depths (not shown) is similar to that of MERRA-Land estimates (Fig. 9a). Similar geographic patterns are also evident in the skill analysis against the WMO in situ snow depth measurements (not shown), which is not surprising because the CMC product is conditioned on WMO snow depth measurements when and where available. Areaweighted pentad anomaly skill versus CMC snow depth is $R=0.51$ for MERRA and $R=0.50$ for MERRALand (Table 3). If the skill average is taken only over CMC grid cells that contain the $583 \mathrm{WMO}$ stations used above, snow depth skill increases to $R=0.60$ for MERRA and $R=0.61$ for MERRA-Land, which is consistent with the skill values assessed directly against the WMO measurements (Table 3 ).

The ERA-I snow depth analysis is largely based on the same in situ snow depth observations used for conditioning the CMC product, although the analysis update is different between the two products (section $2 \mathrm{~b}$ ). Given that these in situ observations were not assimilated into MERRA, it is no surprise that ERA-I anomaly snow depth correlations versus CMC (Fig. 9b) are higher than those of MERRA-Land (or MERRA) versus CMC in eastern Europe, the western half of Russia, and the eastern United States, that is, in regions with a dense network of in situ snow depth stations (Fig. 9c). At the locations of the 583 WMO stations, the average skill (pentad anomaly $R$ vs CMC) of ERA-I snow depth is $R=0.63$, which is slightly higher than MERRA-Land and significantly higher than MERRA skill (see above). However, across the Northern Hemisphere the average correlation of ERA-I snow depth versus CMC is only $R=0.39$ (Table 3 ) and thus considerably lower than that of MERRA-Land (or MERRA) versus CMC. Lower correlations can be seen in eastern Siberia, northern Canada, and Alaska (Fig. 9b). Because there are few stations in these regions, it is not possible to tell which of the products is closer to reality.

By combining CMC snow depths with state-of-the-art snow density estimates (Sturm et al. 2010; section 2b) we extended our evaluation to SWE, a quantity of more relevance to hydrology. The area-weighted skill of SWE pentad anomalies is $R=0.49$ for MERRA, $R=0.49$ for MERRA-Land, and $R=0.38$ for ERA-I (Table 3), comparable to the anomaly $R$ values for snow depth. The spatial pattern of the SWE skills (not shown) is very similar to that of snow depth skills (Figs. 9a,b). Table 3 also lists the bias and RMSE values for MERRA, MERRA-Land, and ERA-I snow depth and SWE versus CMC estimates. By and large, these values are consistent with the snow depth bias and RMSE values versus WMO.

\section{Discussion and conclusions}

Reanalysis estimates of surface meteorological forcings and land surface fields such as snow and soil moisture have proven useful for research into the global water and energy cycles, seasonal climate forecasting, and hydrology. In this paper we assess the skill of soil moisture, snow, and runoff estimates from MERRA against a variety of in situ observations. We also introduce an improved land surface dataset, MERRA-Land, motivated by limitations in MERRA surface meteorological fields, specifically errors in the long-term climatology, the diurnal cycle, and the intensity of precipitation (Figs. 2 and 3). Such deficiencies are indeed typical of global reanalyses and adversely affect the simulation of land surface hydrology. MERRA-Land is a "replay" of the MERRA system's land surface component that benefits from corrections to the precipitation forcing at the pentad scale (using the GPCP v2.1 pentad product) and from revisions to the Catchment model's interception parameters designed to counterbalance known precipitation deficiencies at the subdiurnal scale. The MERRA-Land data products will be made available to the community.

We focus our skill analysis on time series correlation coefficients (versus observations) of pentad average anomalies (soil moisture, snow) or 3-month average anomalies (runoff). Note that because we examine anomalies here, we avoid extracting "trivial" skill from the simulation of the mean seasonal cycle. Generally, the skill of MERRA and MERRA-Land estimates of soil moisture and runoff is comparable to that of ERA-I estimates. Moreover, snow depth and SWE compare well against in situ observations and the state-of-the-art CMC snow analysis. Average (anomaly) skill levels for MERRA and MERRALand surface hydrological variables generally range from $R \sim 0.5$ to $R \sim 0.9$ (Figs. 7, 8, and 9). The skill of MERRALand estimates is higher than that of MERRA estimates by $\Delta R \sim 0.07$ for soil moisture (Fig. 7) and $\Delta R \sim 0.03$ for snow depth (Table 3 ), differences that are statistically significant at the 5\% level. Moreover, MERRA-Land runoff skill is significantly better than that of MERRA for three of the nine large basins examined here (Table 1, Fig. 8). The skill improvements for these variables are typically derived from the GPCP-based precipitation corrections; the revisions to the Catchment model parameters contribute a smaller fraction to the overall improvement. The revised interception model parameters, however, considerably improve the average interception loss fraction (Fig. 4) and contribute to more realistic latent heat fluxes (Fig. 5) in MERRA-Land.

Future reanalysis efforts should include the assimilation of land surface observations. For example, Liu et al. (2011) find that the assimilation of surface soil moisture 
retrievals provides important information that is largely independent of that provided by the precipitation observations. Soil moisture data assimilation has in fact matured to the point where few technical obstacles remain for a long-term soil moisture analysis, though we note that $\mathrm{X}$ - or C-band passive or active microwave observations are not available for the entire satellite era (1979-present). The assimilation of screen-level air temperature and humidity observations has been operational at a number weather centers and is used in ERA-I (section 2b). For the assimilation of satellite-based land surface temperature data, abundant observations are available throughout the satellite era, though appropriate assimilation approaches are considerably less mature (Reichle et al. 2010). The assimilation of snow cover fraction (Zaitchik and Rodell 2009) shows promise, and while MERRA does not contain a snow analysis, most weather centers have been assimilating satellite snow cover observations and in situ snow depth measurements for many years (e.g., Drusch et al. 2004). Even though current-generation satellite retrievals of SWE do not appear to be accurate enough for use in land assimilation, emerging dynamic retrieval approaches may provide useful information (Tedesco et al.2010), and progress has been made toward a radiance-based SWE analysis (Durand and Margulis 2008). Total water storage information from the Gravity Recovery and Climate Experiment (GRACE) has been successfully assimilated into a land surface model (Zaitchik et al. 2008). Advances in the utilization of all of these land data sources are continually proceeding. It seems reasonable to predict that next-generation estimates of global land surface hydrological fields will indeed be based on a comprehensive land surface analysis.

Acknowledgments. Funding for this work was provided by the NASA program on Earth System Science Research using data and products from the Terra, Aqua, and ACRIMSAT satellites. G. De Lannoy is a postdoctoral research fellow supported by the Research Foundation Flanders (FWO), Belgium. B. Forman is a fellow supported by the NASA Postdoctoral Program. Computing was supported by the NASA High End Computing Program. We are grateful for access to the many datasets that supported this work and highly appreciate all those who made them possible, including personnel at USDA, NASA/GSFC, NOAA Climate Prediction Center, Environment Canada, Deutscher Wetterdienst, U.S. Army Corps of Engineers, U.S. Bureau of Reclamation, Columbia River Basin Climate Change Scenarios Database, California Data Exchange Commission, and the European Centre for Medium-Range Weather Forecasts. Thanks also go to G. Huffman and P. Xie for their advice on precipitation data, to M. Tedesco and J. Miller for processing the WMO snow depth data, to T. Martin and G. Starr for the US-SP3 site FLUXNET data, to R. Brown, M. Sturm, and B. Brasnett for the CMC snow analysis data and their support of our study, to D. Miralles for the interception loss fraction data, to C. Jimenez and the GEWEX-LANDFLUX scientists for the multiproduct latent heat data, and to E. Maurer for his assistance in obtaining naturalized streamflow data. Thanks to M. Bosilovich and three anonymous reviewers for many helpful comments.

\section{APPENDIX}

\section{Skill Metric}

Bias is a common problem when validating land model estimates representing scales of $\sim 10-50 \mathrm{~km}$ against pointscale in situ measurements such as the soil moisture and snow depth observations used here-see for instance (Reichle et al. 2004). For soil moisture, the discrepancy between the modeled layer depths and the depths at which in situ sensors are installed can lead to additional bias errors. Specifically, Catchment model surface soil moisture covers the top $2 \mathrm{~cm}$ of the soil column while the in situ surface soil moisture observations were taken at 5-cm depth. Moreover, Catchment model root zone soil moisture covers the top $1 \mathrm{~m}$ of the soil profile and is validated with a depth-weighted average of the SCAN sensors at 5,10 , and $20 \mathrm{~cm}$ because quality-controlled SCAN data at 50 and $100 \mathrm{~cm}$ were too sparse and intermittent (Reichle et al. 2007; Liu et al. 2011).

Fortunately, temporal variations (in a percentile sense) are typically more important for model-based applications (Entekhabi et al. 2010). We therefore first compute the climatological seasonal cycle over the period of interest (separately for each data product), obtain anomalies by subtracting this climatology from the time series, and finally assess skill in terms of correlation coefficients ( $R$ values). For soil moisture and snow depth we constructed pentad-average anomaly time series (because GPCP precipitation estimates are pentad averages). For runoff, we constructed smoothed anomalies by applying a 3-month moving average to the anomalies (because MERRA and ERA-I lack routing schemes). For the soil moisture skill analysis we excluded from the computation of the $R$ values the times and locations for which the soil was frozen. Similarly, for the snow skill analysis we excluded times and locations for which WMO (or CMC) indicated snow-free conditions.

For the results presented here we first computed anomaly $R$ values for each site (or grid cell) and then computed the average skill by averaging the $R$ values across all sites. Common masks and minimum data requirements 
were applied to ensure consistent and sensible estimates of the climatological seasonal cycle on which the anomalies are based. For soil moisture and snow, we also required a minimum of 50 pentad-average anomalies across the multiyear experiment period for computing the anomaly $R$ value.

We also computed approximate $95 \%$ confidence intervals for the $R$ estimates at each site based on the Fisher $Z$ transform. These confidence intervals depend on the estimated $R$ value and on the number of degrees of freedom, which is approximated here by the number of pentad averages that go into the $R$ computation (for soil moisture and snow). Because of the 3-month smoothing we only assume 4 degrees of freedom per data year in the runoff skill analysis. The approximate $95 \%$ confidence intervals for the average skill estimates across all sites were then computed by averaging the $95 \%$ confidence intervals of the $N$ contributing sites and subsequently dividing by the square root of $N$. It is important to stress that the $95 \%$ confidence intervals computed here are only approximations and may underestimate the true widths of the confidence intervals because temporal error correlations may reduce the number of degrees of freedom below the numbers assumed here.

\section{REFERENCES}

Adler, R. F., and Coauthors, 2003: The version-2 Global Precipitation Climatology Project (GPCP) monthly precipitation analysis (1979-present). J. Hydrometeor., 4, 1147-1167.

Berg, A. A., J. S. Famiglietti, M. Rodell, R. H. Reichle, U. Jambor, S. L. Holl, and P. R. Houser, 2005: Development of a hydrometeorological forcing data set for global soil moisture estimation. Int. J. Climatol., 25, 1697-1714, doi:10.1002/ joc.1203.

Bosilovich, M. G., F. R. Robertson, and J. Chen, 2011: Global energy and water budgets in MERRA. J. Climate, 24, 5721-5739.

Brasnett, B., 1999: A global analysis of snow depth for numerical weather prediction. J. Appl. Meteor., 38, 726-740.

Brown, R. D., and B. Brasnett, cited 2010: Canadian Meteorological Centre (CMC) Daily Snow Depth Analysis Data. National Snow and Ice Data Center, Environment Canada. [Available online at http://nsidc.org/data/nsidc-0447.html.]

_ - _ , and D. Robinson, 2003: Gridded North American monthly snow depth and snow water equivalent for GCM evaluation. Atmos.-Ocean, 41, 1-14.

_ C. C. Derksen, and L. Wang, 2010: A multi-data set analysis of variability and change in Arctic spring snow cover extent, 1967-2008. J. Geophys. Res., 115, D16111, doi:10.1029/ 2010JD013975.

Burke, E. J., R. H. J. Perry, and S. J. Brown, 2010: An extreme value analysis of UK drought and projections of change in the future. J. Hydrol., 388, 131-143.

Dai, A., 2006: Precipitation characteristics in eighteen coupled climate models. J. Climate, 19, 4605-4630.

_ , and K. E. Trenberth, 2002: Estimates of freshwater discharge from continents: Latitudinal and seasonal variations. $J$. Hydrometeor., 3, 660-687.
Decker, M., M. Brunke, Z. Wang, K. Sakaguchi, X. Zeng, and M. G. Bosilovich, 2011: Evaluation of the reanalysis products from GSFC, NCEP, and ECMWF using flux tower observations. J. Climate, in press.

Dee, D. P., E. Källén, A. J. Simmons, and L. Haimberger, 2010: Comments on "Reanalyses suitable for characterizing longterm trends." Bull. Amer. Meteor. Soc., 92, 65-70.

—_, and Coauthors, 2011: The ERA-Interim reanalysis: Configuration and performance of the data assimilation system. Quart. J. Roy. Meteor. Soc., 137, 553-597, doi:10.1002/qj.828.

Dirmeyer, P. A., and L. Tan, 2001: A multi-decadal global landsurface data set of state variables and fluxes. COLA Tech. Rep. 102, 43 pp. [Available from the Center for Ocean-LandAtmosphere Studies, 4041 Powder Mill Road, Suite 302, Calverton, MD 20705.]

- X. Gao, M. Zhao, Z. Guo, T. Oki, and N. Hanasaki, 2006: The Second Global Soil Wetness Project (GSWP-2): Multi-model analysis and implications for our perception of the land surface. Bull. Amer. Meteor. Soc., 87, 1381-1397.

Drusch, M., and P. Viterbo, 2007: Assimilation of screen-level variables in ECMWF's Integrated Forecasting System: A study on the impact on the forecast quality and analyzed soil moisture. Mon. Wea. Rev., 135, 300-314.

, D. Vasiljevic, and P. Viterbo, 2004: ECMWF's global snow analysis: Assessment and revision based on satellite observations. J. Appl. Meteor., 43, 1282-1294.

Ducharne, A., R. D. Koster, M. J. Suarez, M. Stieglitz, and P. Kumar, 2000: A catchment-based approach to modeling land surface processes in a general circulation model 2. Parameter estimation and model demonstration. J. Geophys. Res., 105, 24 823-24 838.

Durand, M., and S. A. Margulis, 2008: Effects of uncertainty magnitude and accuracy on assimilation of multiscale measurements for snowpack characterization. J. Geophys. Res., 113, D02105, doi:10.1029/2007JD008662.

Entekhabi, D., R. H. Reichle, R. D. Koster, and W. T. Crow, 2010: Performance metrics for soil moisture retrievals and application requirements. J. Hydrometeor., 11, 832-840.

Guo, Z., P. A. Dirmeyer, Z. Hu, X. Gao, and M. Zhao, 2006: Evaluation of the second Global Soil Wetness Project soil moisture simulations. 2: Sensitivity to external meteorological forcing. J. Geophys. Res., 111, D22S03, doi:10.1029/2006JD007845.

Huffman, G. J., R. F. Adler, D. T. Bolvin, and G. Gu, 2009: Improving the global precipitation record: GPCP version 2.1. Geophys. Res. Lett., 36, L17808, doi:10.1029/2009GL040000.

Jimenez, C., and Coauthors, 2011: Global inter-comparison of 12 land surface heat flux estimates. J. Geophys. Res., 116, D02102, doi:10.1029/2010JD014545.

Kalnay, E., and Coauthors, 1996: The NCEP/NCAR 40-Year Reanalysis Project. Bull. Amer. Meteor. Soc., 77, 437-471.

Kanamitsu, M., W. Ebisuzaki, J. Woollen, S.-K. Yang, J. J. Hnilo, M. Fiorino, and G. L. Potter, 2002: NCEP-DOE AMIP-II Reanalysis (R-2). Bull. Amer. Meteor. Soc., 83, 1631-1643.

Koster, R. D., M. J. Suarez, A. Ducharne, M. Stieglitz, and P. Kumar, 2000: A catchment-based approach to modeling land surface processes in a general circulation model 1. Model structure. J. Geophys. Res., 105 (D20), 24 809-24 822.

, S. P. P. Mahanama, B. Livneh, D. Lettenmaier, and R. H. Reichle, 2010: Skill in streamflow forecasts derived from largescale estimates of soil moisture and snow. Nat. Geosci., 3, 613616, doi:10.1038/ngeo944.

Liu, Q., and Coauthors, 2011: The contributions of precipitation and soil moisture observations to the skill of soil moisture 
estimates in a land data assimilation system. J. Hydrometeor., 12, 750-765.

Mahanama, S. P. P., B. Livneh, R. D. Koster, D. Lettenmaier, and R. H. Reichle, 2012: Soil moisture, snow, and seasonal streamflow forecasts in the United States. J. Hydrometeor., in press.

Miralles, D. G., J. H. Gash, T. R. H. Holmes, R. A. M. de Jeu, and A. J. Dolman, 2010: Global canopy interception from satellite observations. J. Geophys. Res., 115, D16122, doi:10.1029/ 2009JD013530.

Onogi, K., and Coauthors, 2007: The JRA-25 Reanalysis. J. Meteor. Soc. Japan, 85, 369-432.

Qian, T., A. Dai, K. E. Trenberth, and K. W. Oleson, 2006: Simulation of global land surface conditions from 1948 to 2004 . Part I: Forcing data and evaluations. J. Hydrometeor., 7, $953-$ 975.

Reichle, R. H., R. D. Koster, J. Dong, and A. A. Berg, 2004: Global soil moisture from satellite observations, land surface models, and ground data: Implications for data assimilation. J. Hydrometeor., 5, 430-442.

,$-\frac{1}{-}$ P. Liu, S. P. P. Mahanama, E. G. Njoku, and M. Owe, 2007: Comparison and assimilation of global soil moisture retrievals from the Advanced Microwave Scanning Radiometer for the Earth Observing System (AMSR-E) and the Scanning Multichannel Microwave Radiometer (SMMR). J. Geophys. Res., 112, D09108, doi:10.1029/2006JD008033.

_ , S. V. Kumar, S. P. P. Mahanama, R. D. Koster, and Q. Liu, 2010: Assimilation of satellite-derived skin temperature observations into land surface models. J. Hydrometeor., 11, 1103-1122.

Rienecker, M. M., and Coauthors, 2011: MERRA: NASA's Modern-Era Retrospective Analysis for Research and Applications. J. Climate, 24, 3624-3648.

Saha, S., and Coauthors, 2006: The NCEP Climate Forecast System. J. Climate, 19, 3483-3517.

— and Coauthors, 2010: The NCEP Climate Forecast System Reanalysis. Bull. Amer. Meteor. Soc., 91, 1015-1057.

Sakaguchi, K., and X. Zeng, 2009: Effects of soil wetness, plant litter, and under-canopy atmospheric stability on ground evaporation in the Community Land Model (CLM3.5). J. Geophys. Res., 114, D01107, doi:10.1029/2008JD010834.

Schaefer, G. L., M. H. Cosh, and T. J. Jackson, 2007: The USDA Natural Resources Conservation Service Soil Climate Analysis Network (SCAN). J. Atmos. Oceanic Technol., 24, 2073 2077.

Sheffield, J., and E. F. Wood, 2008: Global trends and variability in soil moisture and drought characteristics, 1950-2000, from observation-driven simulations of the terrestrial hydrologic cycle. J. Climate, 21, 432-458.

—, G. Goteti, and E. F. Wood, 2006: Development of a 50-yr high-resolution global dataset of meteorological forcings for land surface modeling. J. Climate, 19, 3088-3111.

Stieglitz, M., A. Ducharne, R. Koster, and M. Suarez, 2001: The impact of detailed snow physics on the simulation of snow cover and subsurface thermodynamics at continental scales. J. Hydrometeor., 2, 228-242.
Sturm, M., J. Holmgren, and G. E. Liston, 1995: A seasonal snow cover classification system for local to global applications. J. Climate, 8, 1261-1283.

_ B. Taras, G. E. Liston, C. Derksen, T. Jonas, and J. Lea, 2010: Estimating snow water equivalent using snow depth data and climate classes. J. Hydrometeor., 11, 1380-1394.

Su, F., and D. P. Lettenmaier, 2009: Estimation of the surface water budget of the La Plata Basin. J. Hydrometeor., 10, 981-998.

Su, H., Z.-L. Yang, R. E. Dickinson, C. R. Wilson, and G.-Y. Niu, 2010: Multisensor snow data assimilation at the continental scale: The value of gravity recovery and climate experiment terrestrial water storage information. J. Geophys. Res., 115, D10104, doi:10.1029/2009JD013035.

Swenson, S., 2010: Assessing high-latitude precipitation from global precipitation analyses using GRACE. J. Hydrometeor., 11, 405-420.

Szczypta, C., and Coauthors, 2011: Verification of the new ECMWF ERA-Interim reanalysis over France. Hydrol. Earth Syst. Sci., 15, 647-666, doi:10.5194/hess-15-647-2011.

Tedesco, M., and J. Miller, cited 2010: Co-registered AMSR-E, QuikSCAT, and WMO data. National Snow and Ice Data Center. [Available online at http://nsidc.org/data/nsidc-0450.html.]

— R. H. Reichle, A. Loew, T. Markus, and J. L. Foster, 2010: Dynamic approaches for snow depth retrieval from spaceborne microwave brightness temperature. IEEE Trans. Geosci. Remote Sens., 48, 1955-1967, doi:10.1109/TGRS.2009. 2036910.

Thorne, P. W., and R. S. Vose, 2010: Reanalyses suitable for characterizing long-term trends. Bull. Amer. Meteor. Soc., 91, 353-361.

Uppala, S. M., and Coauthors, 2005: The ERA-40 Re-Analysis Quart. J. Roy. Meteor. Soc., 131, 2961-3012.

Xie, P., and P. A. Arkin, 1997: Global Precipitation: A 17-year monthly analysis based on gauge observations, satellite estimates, and numerical model outputs. Bull. Amer. Meteor. Soc., 78, 2539-2558.

_ J. E. Janowiak, P. A. Arkin, R. Adler, A. Gruber, R. Ferraro, G. J. Huffman, and S. Curtis, 2003: GPCP pentad precipitation analyses: An experimental dataset based on gauge observations and satellite estimates. J. Climate, 16, 2197-2214.

Yi, Y., J. Kimball, L. Jones, R. H. Reichle, and K. McDonald, 2011: Evaluation of MERRA land surface estimates in preparation for the Soil Moisture Active Passive mission. J. Climate, 24, 3797-3816.

Zaitchik, B. F., and M. Rodell, 2009: Forward-looking assimilation of MODIS-derived snow-covered area into a land surface model. J. Hydrometeor., 10, 130-148.

- - - , and R. H. Reichle, 2008: Assimilation of GRACE terrestrial water storage data into a land surface model: Results for the Mississippi River basin. J. Hydrometeor., 9, 535548.

Zhao, M., S. W. Running, and R. R. Nemani, 2006: Sensitivity of Moderate Resolution Imaging Spectroradiometer (MODIS) terrestrial primary production to the accuracy of meteorological reanalyses. J. Geophys. Res., 111, G01002, doi:10.1029/ 2004JG000004. 